\section{Delving Into COVID-19 Vaccination-Induced Anaphylaxis: Are mRNA Vaccines Safe in Mast Cell Disorders?}

Azenha Rama $\mathrm{T}^{1,2}$, Álvarez-Twose $\mathrm{I}^{3,4}$

${ }^{1}$ Serviço de Imunoalergologia, Centro Hospitalar Universitário São João, Porto, Portugal

${ }^{2}$ Serviço de Imunologia, Faculdade de Medicina da Universidade do Porto, Portugal

${ }^{3}$ Instituto de Estudios de Mastocitosis de Castilla La Mancha, Hospital Virgen del Valle, Toledo, Spain

${ }^{4}$ Spanish Network on Mastocytosis (REMA), Spain

J Investig Allergol Clin Immunol 2021; Vol. 31(2): 193-195 doi: $10.18176 /$ jiaci.0680

Key words: COVID-19. Vaccines. Anaphylaxis. Mastocytosis. Mast cell disorders.

Palabras clave: COVID 19. Vacunas. Anafilaxia. Mastocitosis. Trastornos del mastocito.

\section{To the Editor:}

The COVID-19 outbreak is the worst pandemic of the last 100 years. The rapid development of vaccines $[1,2]$ and the reporting of anaphylactic reactions during the early phase of worldwide mass vaccination $[3,4]$ have raised safety concerns. These are particularly relevant in mastocytosis, mast cell (MC) activation syndrome (MCAS), and hereditary $\alpha$-tryptasemia (HAT), since anaphylaxis is frequent in these disorders.

The first vaccines to receive authorization for emergency use in humans were the mRNA vaccines BNT162b2 (PfizerBioNTech) [1] and mRNA-1273 (Moderna) [2]. No severe systemic reactions were reported during clinical trials, although it should be noted that patients with previous allergic reactions were not included in the trials $[1,2]$.

In novel mRNA vaccines, the synthetic SARS-CoV-2 spike (S) glycoprotein-encoding mRNA is transported via a polyethylene glycol (PEG)-containing envelope into cells, where it is translated into the viral S glycoprotein, against which neutralizing antibodies are subsequently produced $[1,2]$. Because these are the first mRNA vaccines approved for human use, little is known about the underlying mechanisms of the anaphylactic reactions they induce.

The United States Centers for Disease Control and Prevention (CDC) have reported 157 reactions out of almost 6 million doses of mRNA vaccines $[3,4]$, which translates into an overall incidence below $0.003 \%$, with only 1 out of 5 reactions corresponding to anaphylaxis (Table). Thus, the incidence of vaccine-related anaphylaxis is low (ie, 5 out of 1000000 doses), but at least 5 times higher than that reported for other vaccines [5]. The reactions usually developed within 45 minutes after administration and predominantly affected women with a history of allergic reactions (Table). Data from the CDC also show that mRNA-1273 seems to be associated with less frequent adverse reactions but more severe anaphylaxis than BNT162b2 (Table), thus resulting in a similar incidence of severe anaphylaxis with both vaccines (ie, 1 out of 1000000 individuals) [3,4].

It has been suggested that the underlying mechanism for anaphylaxis caused by mRNA vaccines might be IgEmediated hypersensitivity to PEG, a rare but increasingly recognized cause of anaphylaxis $[5,6]$. PEG is a polymer of ethylene oxide that is present in a wide range of drugs, cosmetics, and food additives [5,6]. Moreover, PEG may cross-react with polysorbate, a nonionic surfactant that is also present in other developing SARS-CoV-2 vaccines and widely used in cosmetics, drugs, monoclonal antibodies, and food products $[5,6]$. Anaphylaxis to PEG may also be due to complement activation and release of anaphylatoxin caused by antibodies against PEG [5]. IgE-mediated anaphylaxis caused by excipients has been reported in patients with a previous history of allergic reactions induced by drugs that may contain PEG (eg, corticosteroids), polysorbate (eg, influenza vaccines), and tromethamine (eg, gadolinium) $[3,4]$. Besides PEG, the mRNA-1273 vaccine contains tromethamine, which is present in contrast media and other health care and cosmetic products and was recently involved in an allergic reaction to gadolinium-based contrast media $[7,8]$. Therefore, a thorough clinical history including previous allergic reactions to drugs and self-care products is mandatory when assessing whether a patient can safely receive one of these vaccines.

At present, little is known about the safety of these new COVID-19 vaccines in patients at potential risk of anaphylaxis, such as those with mastocytosis. Moreover, anaphylaxis is frequently the presenting feature of systemic mastocytosis in a significant proportion of patients without skin involvement and for whom the Spanish Network on Mastocytosis (REMA) score constitutes a validated, highly efficient predictive tool [9]. The scores assigned in this model include sex (male, +1 ; female -1 ), symptoms (absence of pruritus, urticaria, and angioedema, +1 ; presence of pruritus, urticaria, and/or angioedema, -2 ; presyncope and/or syncope +3 ), and baseline serum tryptase $(<15 \mu \mathrm{g} / \mathrm{L},-1 ;>25 \mu \mathrm{g} / \mathrm{L},+2)$. A REMA score $\geq 2$ predicts the presence of SM with a sensitivity and specificity of $92 \%$ and $81 \%$, respectively. The high frequency of women (94\%) with mucocutaneous symptoms in the absence of cardiovascular manifestations $(87 \%)$ among the cases of vaccine-related anaphylaxis reported by the CDC translates into a score $<2$ (ie, low probability of systemic mastocytosis) in most cases, without the need to determine baseline serum tryptase (Table).

BNT162b2 was recently reported to be safe with premedication in mastocytosis patients with severe MC mediator-related symptoms [10]. Consistent data on the need for and type of preventive measures in patients with MC-related disorders receiving COVID-19 vaccines are still lacking. We consider all adult patients with mastocytosis, MCAS, and HAT to be candidates for these vaccines, except in cases of a history of allergic reactions caused by any of the aforementioned components of the vaccine or by the first dose of the vaccine. Until further information is available, we recommend premedication with at least an $\mathrm{H}_{1}$ histamine blocker 1 hour before vaccination. The vaccine should be administered by trained staff in appropriate health care facilities (ie, hospital with available intensive care unit) and under 
Table. Main Characteristics of Allergic Reactions and Anaphylaxis Reported by the United States Centers for Disease Control After Administration of mRNA Vaccines Against SARS-CoV-2

\begin{tabular}{|c|c|c|c|c|}
\hline & \multicolumn{2}{|c|}{$\begin{array}{c}\text { BNT162b2 } \\
\text { (Pfizer-BioNTech) }\end{array}$} & \multicolumn{2}{|c|}{$\begin{array}{l}\text { mRNA-1273 } \\
\text { (Moderna) }\end{array}$} \\
\hline & $\begin{array}{l}\text { Anaphylaxis } \\
(n=21)\end{array}$ & $\begin{array}{l}\text { Allergic Reaction } \\
\qquad(\mathrm{n}=83)\end{array}$ & $\begin{array}{l}\text { Anaphylaxis } \\
(n=10)\end{array}$ & $\begin{array}{l}\text { Allergic Reaction } \\
\qquad(\mathrm{n}=43)\end{array}$ \\
\hline Female & $90 \%$ & $90 \%$ & $100 \%$ & $91 \%$ \\
\hline $\begin{array}{l}\text { Time from administration } \\
\quad<15 \mathrm{~min} \\
\quad<45 \mathrm{~min}\end{array}$ & $\begin{array}{c}13(2-150) \\
71 \% \\
90 \%\end{array}$ & $\begin{array}{c}12(<1-1200) \\
74 \% \\
88 \%\end{array}$ & $\begin{array}{c}7.5(1-45) \\
90 \% \\
100 \%\end{array}$ & $\begin{array}{c}15(<1-1440) \\
51 \% \\
78 \%\end{array}$ \\
\hline Mucocutaneous without $\mathrm{CV}^{\mathrm{b}}$ & $21(100 \%)$ & NA & $7(70 \%)$ & NA \\
\hline Treatment with epinephrine & $90 \%$ & NA & $100 \%$ & NA \\
\hline Hospitalization & $19 \%$ & NA & $60 \%$ & NA \\
\hline Admittance to ICU & $14 \%$ & NA & $50 \%$ & NA \\
\hline $\begin{array}{l}\text { History of allergy } \\
\text { Insect stings } \\
\text { Vaccines } \\
\text { Drugs } \\
\text { Contrast media } \\
\text { Food }\end{array}$ & $\begin{array}{c}81 \% \\
10 \% \\
10 \% \\
38 \% \\
5 \% \\
24 \%\end{array}$ & $\begin{array}{l}67 \% \\
\text { NA } \\
\text { NA } \\
\text { NA } \\
\text { NA } \\
\text { NA }\end{array}$ & $\begin{array}{c}90 \% \\
0 \% \\
0 \% \\
60 \% \\
20 \% \\
10 \%\end{array}$ & $\begin{array}{l}60 \% \\
\text { NA } \\
\text { NA } \\
\text { NA } \\
\text { NA } \\
\text { NA }\end{array}$ \\
\hline History of prior anaphylaxis & $33 \%$ & NA & $50 \%$ & NA \\
\hline Incidence (per 100000 doses) & 1.1 & 4.4 & 0.2 & 1.1 \\
\hline Number of doses administered & \multicolumn{2}{|c|}{1893360} & \multicolumn{2}{|c|}{4041396} \\
\hline Excipients potentially involved & \multicolumn{2}{|c|}{ PEG-2000 } & \multicolumn{2}{|c|}{ PEG-2000, tromethamine } \\
\hline
\end{tabular}

Adapted from $[4,5]$.

Abbreviations: CV, cardiovascular symptoms; ICU, intensive care unit; NA, not available; PEG, polyethylene glycol.

a Median time in minutes (range).

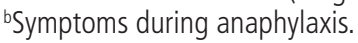

medical surveillance that should be maintained for 45 minutes. In high-risk patients (eg, patients with a previous history of immediate reactions to contrast media, monoclonal antibodies or drugs containing PEG, polysorbate, or tromethamine), the decision on whether the patient should be vaccinated must be made on an individual basis. If the assessment supports vaccination, a reasonable approach would comprise more intensive premedication, including $\mathrm{H}_{1}$ plus $\mathrm{H}_{2}$ antihistamines 1 hour before vaccination, and montelukast 24 and 1 hour before vaccination, followed by an observation period of 90 minutes. Specifically, in patients with non-IgE-mediated reactions potentially associated with tromethamine (eg, contrast media, intravenous dexketoprofen, ketorolac, and fosfomycin), tromethamine-free vaccines should be selected.

The next few months will be crucial for the success of COVID-19 vaccination, which will be the first step in resolving the current pandemic. Although severe allergic reactions are being increasingly reported, the risk of anaphylaxis in patients with mastocytosis seems to be low, provided that appropriate premedication is given. As the mass vaccination campaign moves forward, more information should be gathered in order to establish whether more specific preventive protocols are needed for these patients. Meanwhile, the watchword should be "vaccinate".

\section{Funding}

The authors declare that no funding was received for the present study.

\section{Conflicts of Interest}

The authors declare that they have no conflicts of interest.

\section{References}

1. Polack FP, Thomas SJ, Kitchin N, Absalon J, Gurtman A, Lockhart S, et al. Safety and Efficacy of the BNT162b2 mRNA Covid-19 Vaccine. N Engl J Med. 2020;383(27):2603-15.

2. Baden LR, El Sahly HM, Essink B, Kotloff $K$, Frey S, Novak R, et al. Efficacy and Safety of the mRNA-1273 SARS-CoV-2 Vaccine. N Engl J Med. 2021;384(5):403-16.

3. Shimabukuro $T$, Nair N. Allergic Reactions Including Anaphylaxis After Receipt of the First Dose of Pfizer-BioNTech COVID-19 Vaccine. JAMA 2021;325(8):780-81.

4. CDC COVID-19 Response Team; Food and Drug Administration. Allergic Reactions Including Anaphylaxis After Receipt of the First Dose of Moderna COVID-19 Vaccine-United States, 
December 21, 2020-January 10, 2021. MMWR Morb Mortal Wkly Rep. 2021;70.

5. Castells MC, Phillips EJ. Maintaining Safety with SARSCoV-2 Vaccines. N Engl J Med. [published online ahead of print December 30, 2020]. https://doi.org/10.1056/ NEJMra2035343

6. Banerji A, Wickner PG, Saff R, Stone CA, Jr., Robinson LB, Long AA, et al. mRNA Vaccines to Prevent COVID-19 Disease and Reported Allergic Reactions: Current Evidence and Suggested Approach. J Allergy Clin Immunol Pract. 2021;\$22132198(20)31411-2.

7. Lukawska J, Mandaliya D, Chan AWE, Foggitt A, Bidder T, Harvey J, et al. Anaphylaxis to trometamol excipient in gadolinium-based contrast agents for clinical imaging. J Allergy Clin Immunol Pract. 2019;7(3):1086-7.

8. Caballero ML, Quirce S. Immediate Hypersensitivity Reactions Caused by Drug Excipients: A Literature Review. J Investig Allergol Clin Immunol. 2020;30(2):86-100.

9. Alvarez-Twose I, Gonzalez de Olano D, Sanchez-Munoz L, Matito A, Esteban-Lopez MI, Vega A, et al. Clinical, biological, and molecular characteristics of clonal mast cell disorders presenting with systemic mast cell activation symptoms. J Allergy Clin Immunol. 2010;125(6):1269-78 e2.
10. Rama TA, Moreira A, Castells M. mRNA COVID-19 vaccine is well tolerated in patients with cutaneous and systemic mastocytosis with mast cell activation symptoms and anaphylaxis. J Allergy Clin Immunol. 2021;147(3):877-8.

- Manuscript received February 4, 2021; accepted for publication February 11, 2021.

\section{- Iván Álvarez-Twose}

Instituto de Estudios de Mastocitosis de Castilla-La Mancha (CLMast) - CSUR de Mastocitosis Hospital Virgen del Valle, Complejo Hospitalario de Toledo

Ctra. de Cobisa, s/n 45071 Toledo, Spain

E-mail: ivana@sescam.jccm.es 